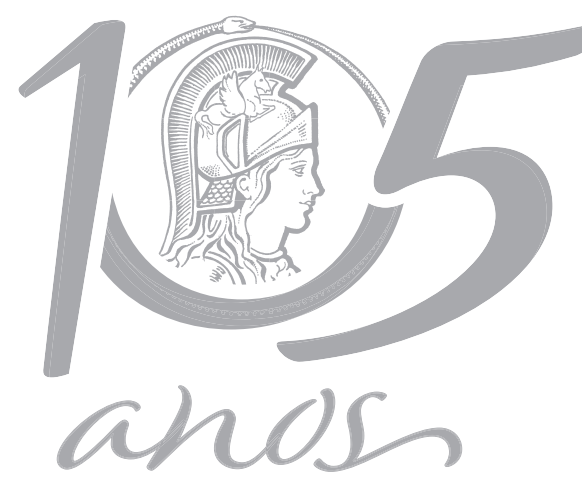

$1916 \cdot 2021$

\title{
HEALTH SCIENCES \\ COVID-19 pandemic and the answer of science: a year in review
}

\author{
EDUARDO A. OLIVEIRA, MARIA CHRISTINA L. OLIVEIRA, DANIELLA B. MARTELLI, \\ ENRICO ANTÔNIO COLOSIMO, LUDMILA R. SILVA, KATHARINA LANZA, HERCÍLIO \\ MARTELLI-JÚNIOR \& ANA CRISTINA SIMÕES E SILVA
}

\begin{abstract}
The world is looking forward to a prompt response by the scientific community in order to overcome the first pandemic of the $21^{\text {st }}$ century. This study aimed to provide an overview of scientific output on COVID-19 during its first year. We assembled information regarding 60,830 articles related to COVID-19 indexed in the WoS database from January 24 to December 13, 2020. Only 4 countries accounted for about $60 \%$ of the articles (USA, China, Italy, and England) and 12 countries accounted for about $95 \%$ of the world scientific output on COVID-19 (USA, China, Italy, England, India, Canada, Germany, Spain, Australia, Brazil, Iran, and Turkey). 25 research centers around the world contributed with more than 500 papers on COVID-19. Papers were scattered throughout 6,133 journals, with 12 journals with $>250$ articles. 20 articles (0.03\%) have already received more than the 1,000 citations. The response of the scientific endeavor to this acute global public health emergency has been fast and robust. The overview provided by the analysis of the scientific response to the pandemic may contribute to further studies aiming to evaluate the impact and changes in the scientific endeavor for the next years in light of the forthcoming new world framework.
\end{abstract}

Key words: COVID-19, research evaluation, scientific production, science policy.

\section{INTRODUCTION}

In early December 2019, a cluster of pneumonia cases of unknown origin was identified in Wuhan, the capital city of Hubei province, China (Lu et al. 2020a). On January 7, 2020 a novel coronavirus was identified from a throat swab sample of a patient (Chen et al. 2020), and by January 20, the virus was isolated and sequenced (Zhou et al. 2020). The new virus was then named SARSCoV-2/ human/Wuhan/X1/2019 (SARS-CoV-2) (Coronaviridae Study Group of the International Committee on Taxonomy of Viruses, 2020). On March 11, 2020, the WHO announced that the disease caused by SARS-CoV-2, designated coronavirus disease 2019 (COVID-19), should be considered a global pandemic (WHO 2020).
The first pandemic of the 21st century has been overwhelming healthcare systems and is placing unprecedented economic pressure on global society. Therefore, the entire world is looking forward to a prompt response by the scientific community in order to overcome this unparalleled crisis.

The answer has been quick and robust. The global pandemic stimulated extraordinary amounts of scientific investigation around the world. The virus first appeared in the scholarly literature on January 24, 2020 (Huang et al. 2020), and, since then, medical researchers and virologists have been working to isolate and identify the virus, determine its etiology, and define the risk factors for adverse outcomes, conducting research on drug and vaccine 
development (Fry et al. 2020). Since January 2020, the pace of achievements has been astonishing. Nevertheless, this large amount of information produced about COVID-19 is so abundant and dynamic that some concerns have been recently raised regarding some aspects of the scientific enterprise, including research funding and scientific publishing standards. During the pandemic, journals are racing to publish COVID-19 papers and, accordingly, the peer review process has been modified regarding COVID-19 related research submissions (Bauchner et al. 2020).

We developed a database of articles indexed in Web of Science (WoS) during the first sixmonths of the COVID-19 crisis up to December 13 with the aim to understand the scientific impact of the response to the pandemic. We assembled information regarding 60,803 papers published in approximately 6,000 journals, covering an array of disciplines that have already made fundamental contributions to our understanding of the many aspects of this new disease. Based on a comprehensive analysis of this database, this study aimed to provide an overview of the global scientific response to an unparalleled challenge to our society.

\section{MATERIALS AND METHODS}

A complete dataset of scientific articles on coronavirus-related research between January 1, 2020 and December 13, 2020 was extracted from the Clarivate Web of Science (WoS). The following consistent set of keywords was used in searches in the Title/Abstract/Keywords of each article in the respective databases: "COVID-19" OR "2019-nCoV" OR "coronavirus" OR "Corona virus" OR "SARS-COV". Using the search procedure outlined, the data comprise a total of 60,803 coronavirus-related articles. Among these data, 30,152 (42\%) were classified by WoS database as "articles', 10,919 (25\%) as "editorial material", 10,556 (20.4\%) as "letter", 6,3041 (97\%) as "review", and 8,418 as "early access" from each article we retrieved the following data: date of publication, country, address of the institutions, research institutions, journals, and subjects. In addition, we also classified the journals regarding their discipline and scope (for instance, virology, immunology, clinical medicine, and so on). The classification scheme proposed by the WoS was used to assign journals to science fields. In about $8 \%$ of the articles, the information about the country and institution involved could not be retrieved. We retrieved data regarding the 2019 scientific output of each country from the SCImago website https://www.scimagojr.com/. SCImago is an online platform that ranks journals and countries in several knowledge fields based on bibliometric indicators, including, among others, the total number of documents per year, citable documents, citations per document, and the $\mathrm{H}$-index.

\section{Statistical analysis}

We downloaded to a spreadsheet all the variables of interest from the above-mentioned public databases and integrated all of them into a dedicated database using the Statistical Package for Social Science for Windows (SPSS) version 18.0. We used descriptive statistics analysis. Continuous data were reported as medians and interquartile range (IQ) or means and standard deviation (SD), when appropriate. Graphs were also constructed using Tableau Public, 2019 version (https://public.tableau. com). 


\section{RESULTS}

\section{Pace of scientific production about Covid-19}

Over the 12-month span, the search retrieved 60,803 articles scattered throughout 6,133 journals covering an array of disciplines. The date of publication was available for 48,029 records (78\%). Figure 1 illustrates the exponential increment of scientific production regarding COVID-19 in 2020. it was published Only about $26 \%(1,249 / 13,451)$ of the papers were published in the first trimester, while 10,880 (22.6\%) were published in the second; $48 \%$ in the third, and the remaining $27 \%$ in the last. The average output was about 67 papers per day in the first semester compared with a mean of 217 papers per day in the second trimester.

\section{Countries and Research Institutions}

Regarding production by country, 3,247 records (5.3\%) did not contain data in the field. There were 179 countries with at least one paper on COVID-19. However, the distribution of production was heavily skewed. Only 4 countries accounted for about $60 \%$ of all articles (USA, China, Italy, and England) and 12 countries accounted for about $95 \%$ of the world scientific output on COVID-19 (USA, China, Italy, England, India, Canada, Germany, Spain, Australia, Brazil, Iran, and Turkey). Figure 2 shows the most productive countries, with more than 1,300 papers over the first 12-months. Regarding the production by country, 3,247 records (53\%) did not contain data in the field. Regarding the research institutions involved in the scientific output, we found 25 research centers around the world that contributed more than 500 articles on COVID-19. The most productive institutions included Harvard University with 1,821 papers (3\%), the University of London with 1,795 papers (about 29\%), the University of California System (23\%), Huazhong University of Science Technology (22\%), and Harvard Medical School

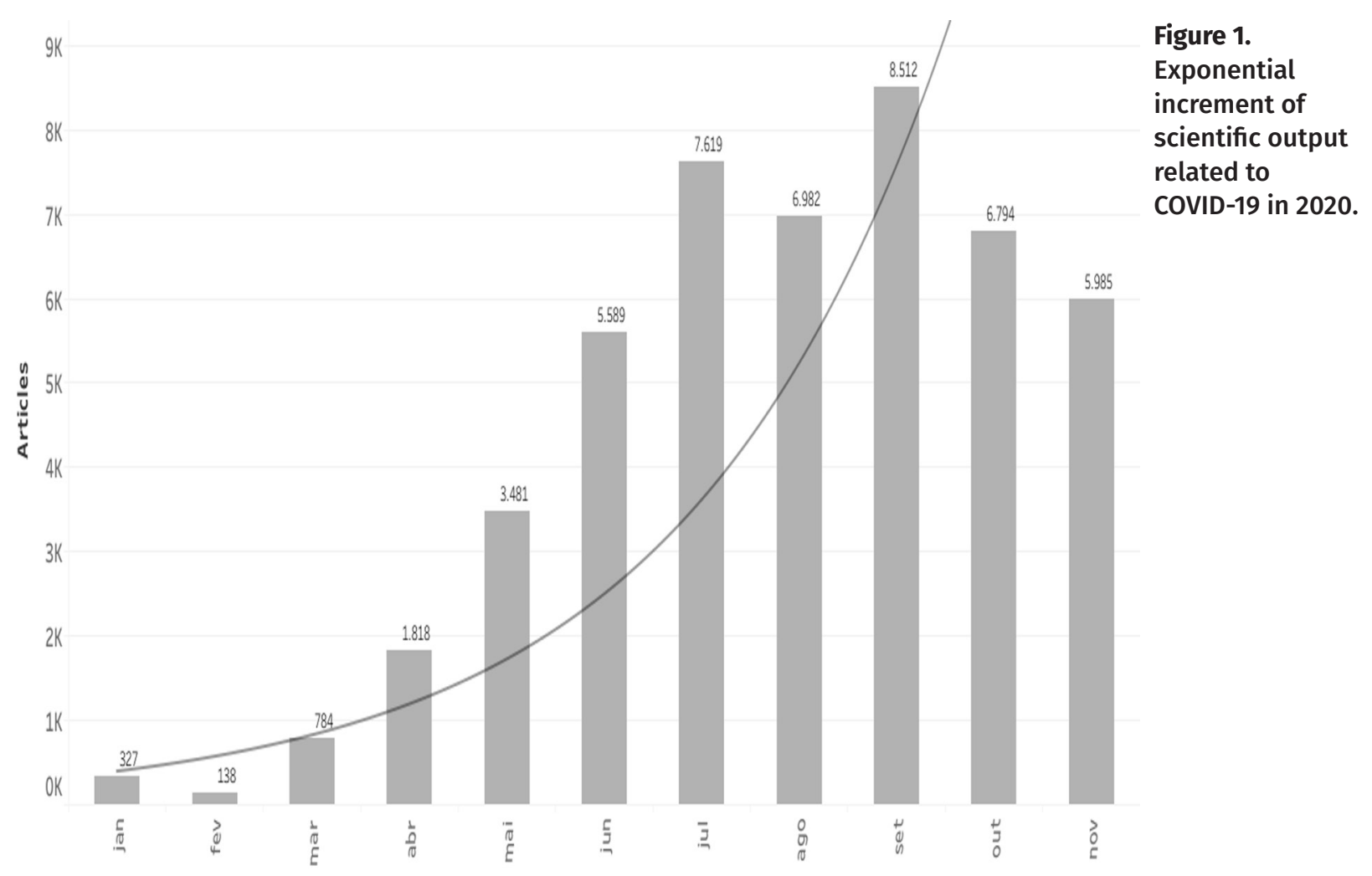


(1.8\%). Figure 3 shows the 25 most productive institutions over the first 6 -months. The majority of these most productive institutions were from the US (13) and England (4).

\section{Journals and Categories}

The scientific output was distributed through 6,133 journals from all over the world. Figure 4 shows the 12 journals with more than 250 articles published in 2020. These journals accounted for about $11 \%$ of the papers concerning the novel coronavirus, led by the Lancet family (21\%), BMJ
(18\%), Nature family (15\%), J Med Virol. (12\%), and the JAMA family (11\%).

The articles about COVID-19 belonged to 238 different categories in the WoS database. As expected, the main categories of the articles concerning this new disease were those dealing with fundamental aspects of the clinical and epidemiological issues of the pandemic. The journals included in the Medicine (General and Internal) category accounted for 7,728 papers (127\%), followed by journals included in the category of Public Environmental Occupational Health (4,697; 77\%), Infectious diseases (3,066;

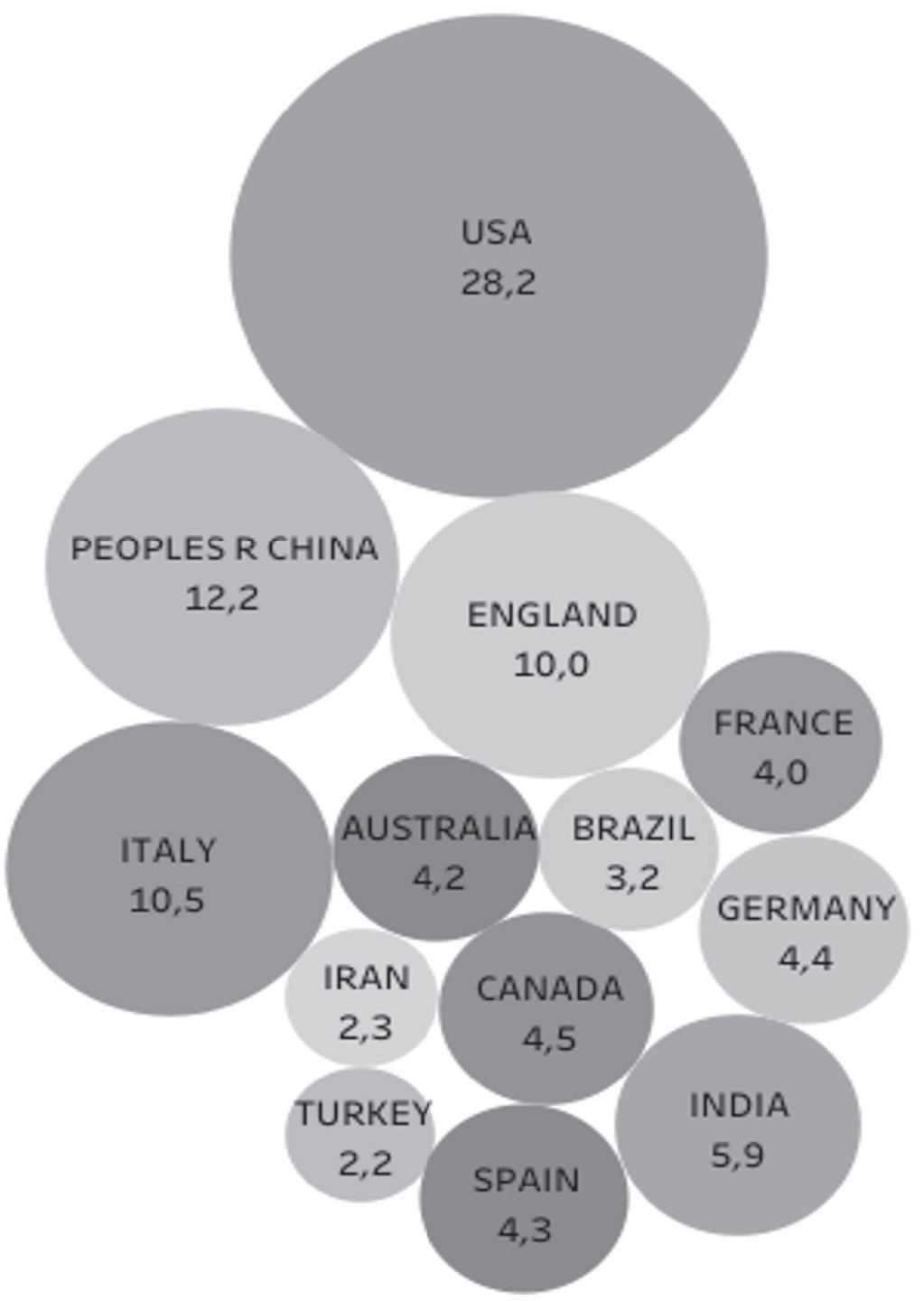

\author{
Figure 2. Output of \\ scientific articles \\ related to COVID-19 \\ by the 12 most \\ productive countries.
}


$5 \%)$, Cardiology $(2,631 ; 43 \%)$, and Surgery $(2,539$; $41 \%)$. Other frequent categories were Virology, Pharmacology, Emergency/critical care, and medical specialties such as Radiology, Oncology, and Pediatrics. Figure 5 displays the main categories that contributed to the literature about the novel coronavirus, highlighting those with more than 600 papers (1\%).

\section{Citations}

Over the 12-month period, 20 articles (0.03\%) had already received more than the 1,000 citations. Table I presents the 15 papers most cited up to December 2020. Of the 20 papers, 10 were from China, 2 from the US, and 1 each from Germany, the United Kingdom, and France. The majority of the most cited articles were published in Lancet and affiliated journals (33\%) and in NEJM (27\%). Most of these articles dealt with the clinical features (47\%) and pathophysiology (40\%) of the new disease.

\section{Subjects}

Regarding the title contents, the most frequent terms included impact $(2,952,48 \%)$, clinical $(2,900,47 \%)$, case $(2,723,45 \%)$, response $(2,252$, $37 \%)$, risk $(2,142,35 \%)$, management $(2,019$, $33 \%)$, treatment $(1,973,32 \%)$, testing $(1,731,28 \%)$, immunity/immunology (1,650, 27\%), cancer $(1,506,25 \%)$, and mental health $(1,471,24 \%)$. Of note, among the 60,830 articles only 757 (124\%) and 736 (120\%) had the terms vaccine and clinical

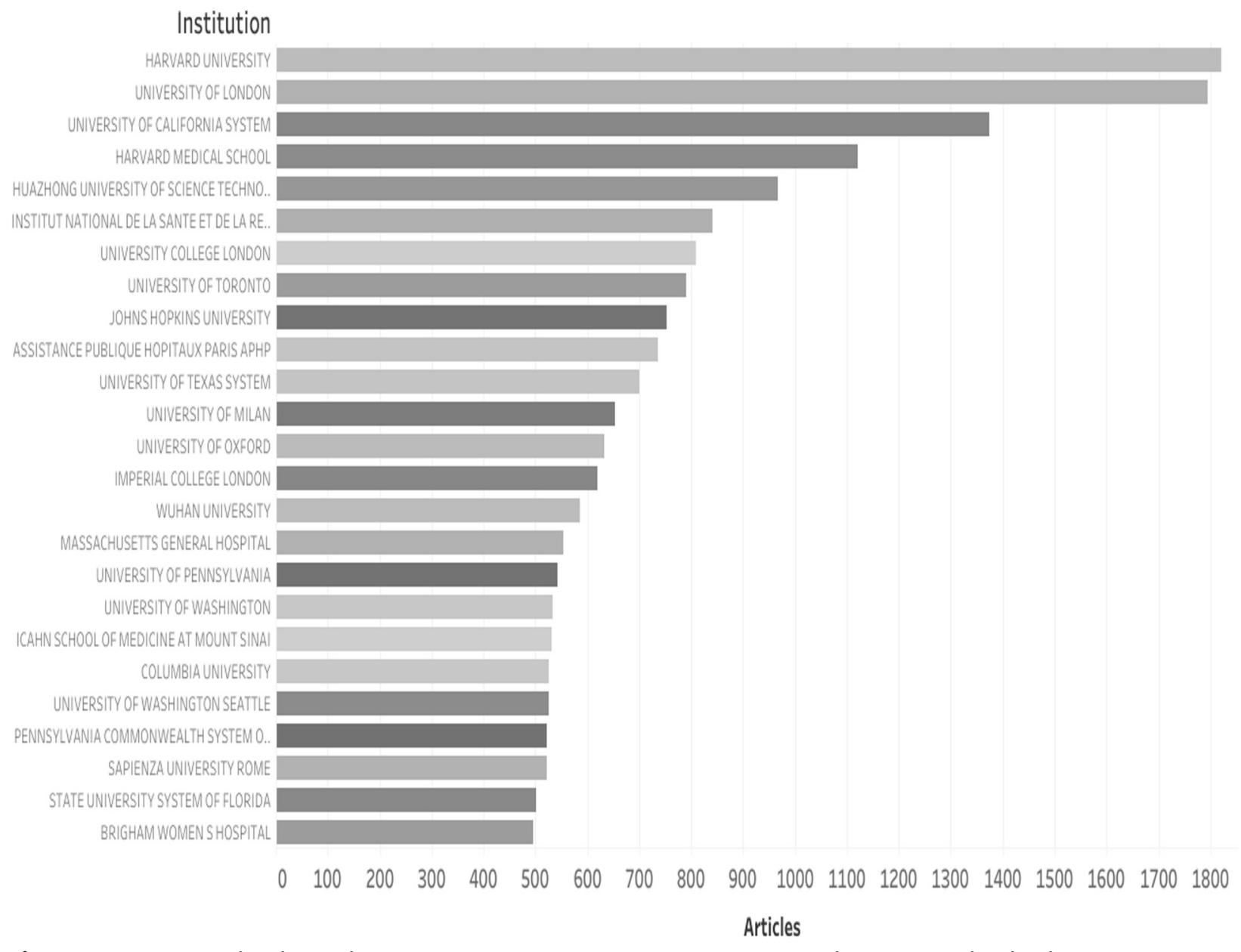

Figure 3. Output of scientific articles related to COVID-19 by the most productive research institutions. 
Table I. The 15 most cited COVID-19 articles until December 13, 2020.

\begin{tabular}{|c|c|c|c|c|c|c|}
\hline Authors & Country & Journal & Date & Theme & Citations & $\begin{array}{c}\text { Mean } \\
\text { Citations } \\
\text { month }\end{array}$ \\
\hline Guan, WJ et al. & China & N Engl J Med & $2020 / 02 / 29$ & Clinical & 5,095 & 526 \\
\hline Zhou, FT et al. & China & Lancet & $2020 / 03 / 15$ & Clinical & 4,335 & 481 \\
\hline Zhu, N. et al & China & N Engl J Med & $2020 / 03 / 28$ & Clinical & 4,301 & 474 \\
\hline Zhou, P. et al & China & Nature & $2020 / 03 / 02$ & Clinical & 3,303 & 367 \\
\hline Wu, Z. et al. & China & JAMA & $2020 / 02 / 25$ & Clinical & 2,518 & 252 \\
\hline Hoffmann, M. et al & Germany & Cell & $2020 / 04 / 16$ & Pathophysiology & 2,338 & 311 \\
\hline Lu, R. et al & China & Lancet & $2020 / 02 / 22$ & Genomic & 2,169 & 217 \\
\hline Mehta, P. et al. & UK & Lancet & $2020 / 03 / 21$ & Pathophysiology & 1,764 & 207 \\
\hline Xu, Z. et al & China & $\begin{array}{c}\text { Lancet Respir } \\
\text { Med }\end{array}$ & $2020 / 05 / 10$ & Pathophysiology & 1,707 & 262 \\
\hline Yang, X. et al & China & $\begin{array}{c}\text { Lancet Respir } \\
\text { Med }\end{array}$ & $2020 / 05 / 10$ & Clinical & 1,701 & 261 \\
\hline van Doremalen, N. et al & USA & N Engl J Med & $2020 / 04 / 16$ & Pathophysiology & 1,591 & 198 \\
\hline Gautret, P. et al & France & $\begin{array}{l}\text { Int J Antimicrob } \\
\text { Agents }\end{array}$ & $2020 / 07 / 01$ & Treatment & 1,319 & 239 \\
\hline Wrapp, D. et al & USA & Science & $2020 / 03 / 13$ & Pathophysiology & 1,214 & 134 \\
\hline Zou, L. et al. & China & N Engl J Med & $2020 / 02 / 20$ & Pathophysiology & 1,165 & 117 \\
\hline Wu, C. & China & $\begin{array}{l}\text { JAMA Internal } \\
\text { Med }\end{array}$ & $2020 / 07 / 15$ & Clinical & 1,154 & 192 \\
\hline
\end{tabular}

trials in the title, respectively. Of note, most of these articles were comments or protocols regarding vaccine and clinical trials. The first results of a randomized clinical trial (RCT) on COVID-19 treatment were reported on March 18, involving a trial with Lopinavir-Ritonavir, both of them antiviral HIV medications repurposed as experimental drugs for SARS-CoV-2. The first RCT with an effective repurposed drug was reported on July 17, involving a trial with dexamethasone which showed a reduction of mortality of severely affected patients. Figure 6 illustrates the timeline of the milestones regarding drugs and vaccine trials. Interestingly, trials of possible repurposed drugs first predominated, followed by trials of candidate vaccines culminating with the beginning of phase 1 vaccination for healthcare professionals in the United Kingdom on $12 / 8 / 2020$.

\section{National Contribution}

Brazil is part of the 12 countries group accounting for $95 \%$ of the world scientific output on COVID-19, adding up to 2,582 papers on WoS database in 2020. Regarding affiliations, the most frequent institution was University of São Paulo, accomplishing for $21.0 \%$ of Brazilian papers and placing $29^{\text {th }}$ in the international ranking on the number of papers published in 2020. The other representative institutions are Oswaldo Cruz Foundation (7.9\% of national research), Federal University of São Paulo (7.8\%), Federal University of Rio de Janeiro (6.6\%), Federal University of Minas Gerais (5\%) and 


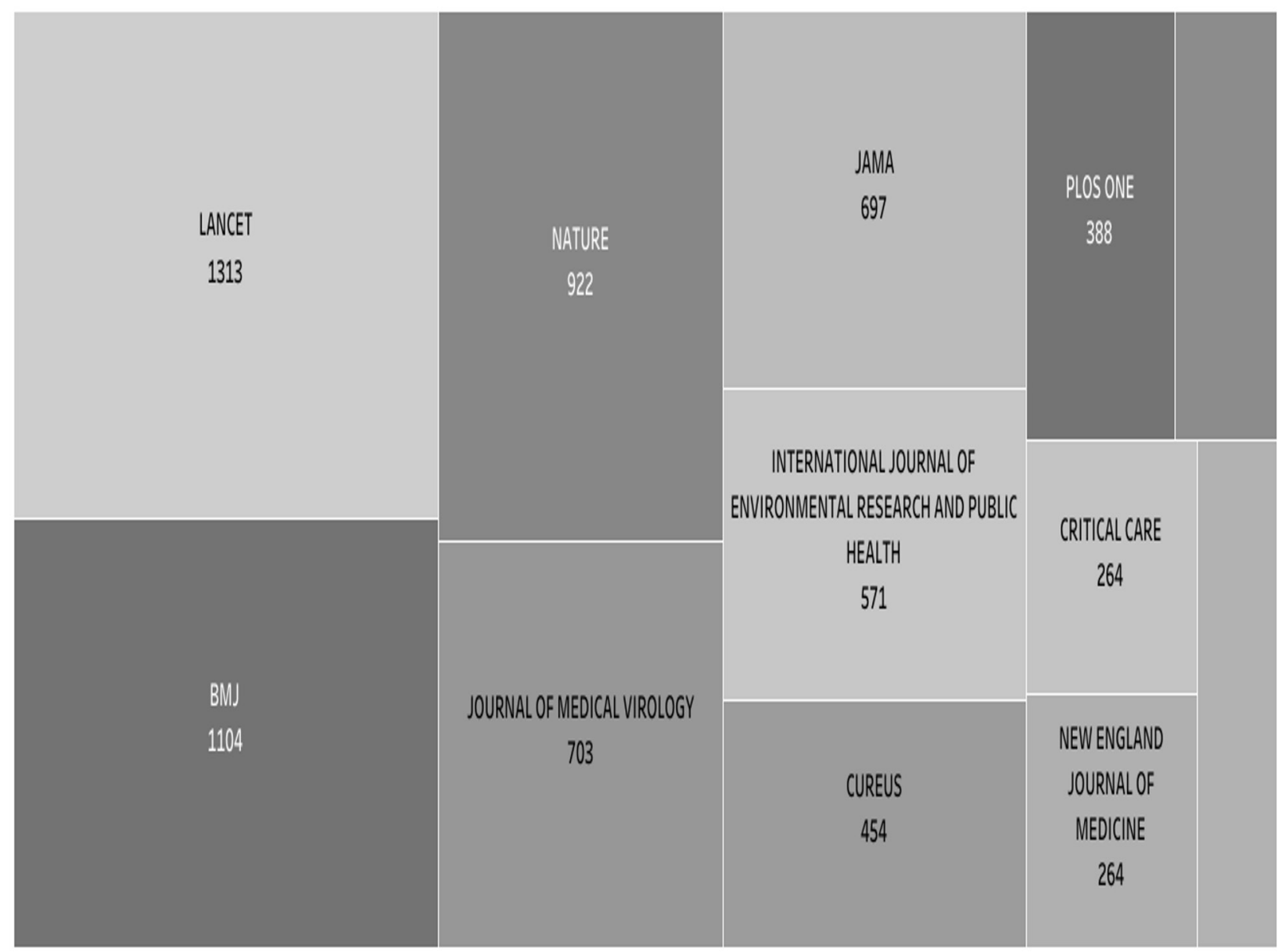

Figure 4. Output of scientific articles related to COVID-19 by the most productive journals.

State University of Campinas (4.8\%). Collectively, the six institutions comprise more than $50 \%$ of Brazilian contribution to the scientific research on COVID-19. The most frequent categories in the WoS database were Public Environmental Occupational Health $(323 ; 12.5 \%)$, Medicine (General and Internal) (281; 10.9\%), Infectious Diseases (116; 4.5\%), Tropical Medicine (93; $3.4 \%$ ) and Multidisciplinary Sciences (88; 3.3\%). The most cited paper up to December 2020 received 555 citations and exposed about Fair Allocation of Scarce Medical Resources in the Time of Covid-19. Among the 2,582 articles, only $16(0.59 \%)$ and 17 (0.65\%) had the terms vaccine and clinical trials in the title, respectively. The three most important funding agents were the
National Council for Scientific and Technological Development (CNPq), supporting $12.7 \%$ of the 2,582 papers, followed by the Coordination for the Improvement of Higher Education Personnel (CAPES) (9.6\%) and the São Paulo Research Foundation (FAPESP) (5.2\%).

\section{DISCUSSION}

The findings of this descriptive study of the scientific production related to COVID-19 highlight the impressive pace of the response of the world scientific community to this unparalleled challenge posed by the first pandemic of the 21st century. In 2020, about 


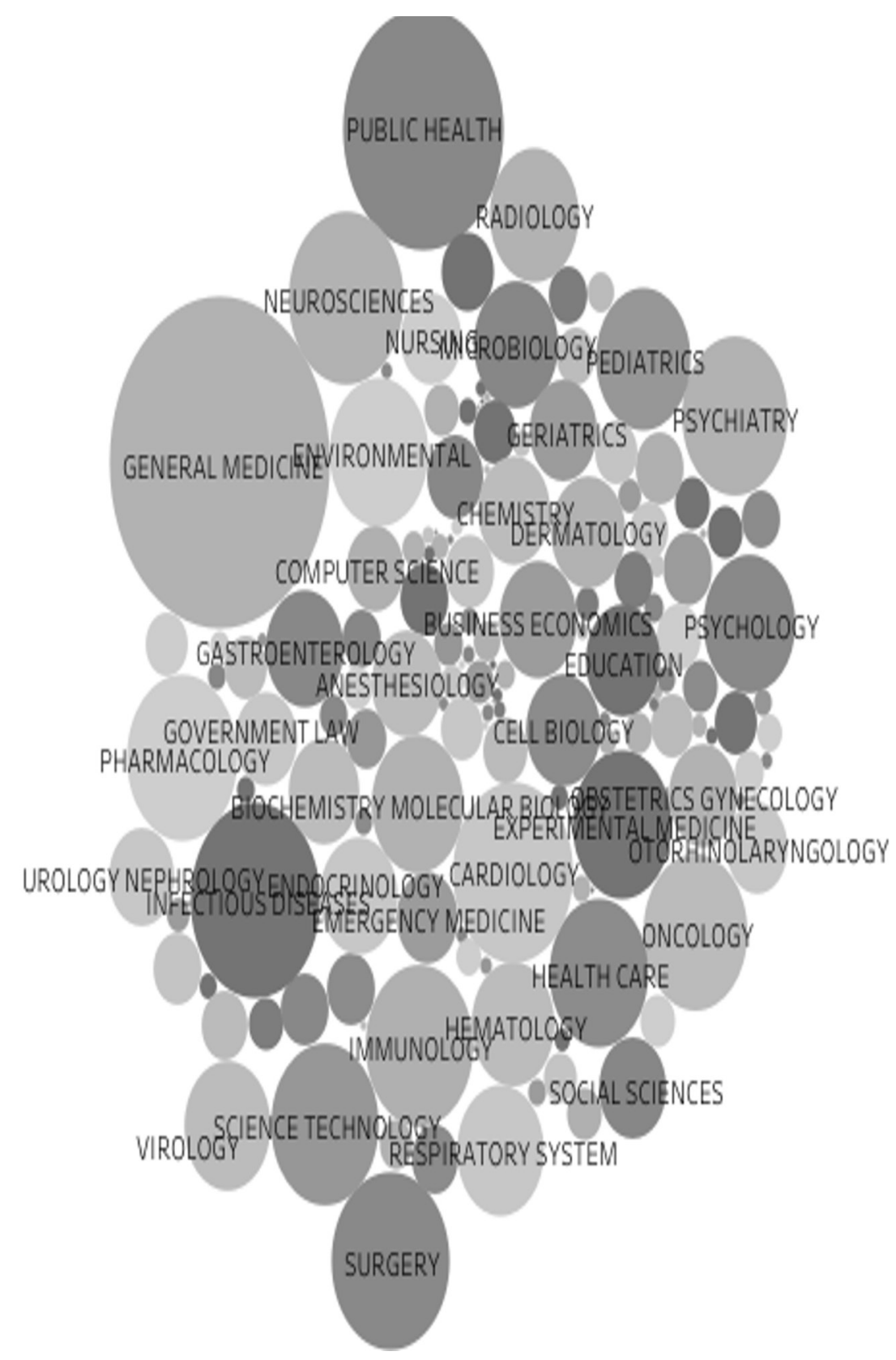

\author{
Figure 5. Subject \\ categories of the \\ scientific articles \\ related to COVID-19 \\ indexed by WoS
}

60,0000 articles were indexed in WoS, not to mention 11,000 additional articles that were deposited in preprint repositories such as the medRxiv website. Thus, the pace of the global scientific output on COVID-19 averaged 110 papers a day, mostly concentrated in the second trimester of 2020. In a recent editorial regarding the development of a vaccine against COVID-19, Heaton (2020) pointed out that the world has now witnessed the compression of 6 years of work into 6 months. We believe that this observation is also pertinent to the pace of the overall scientific production on COVID-19. For instance, during the same period, this output was greater than that regarding other current highly productive traditional topics such as hypertension (10.120 papers indexed by WoS) and obesity (12,220 papers). 


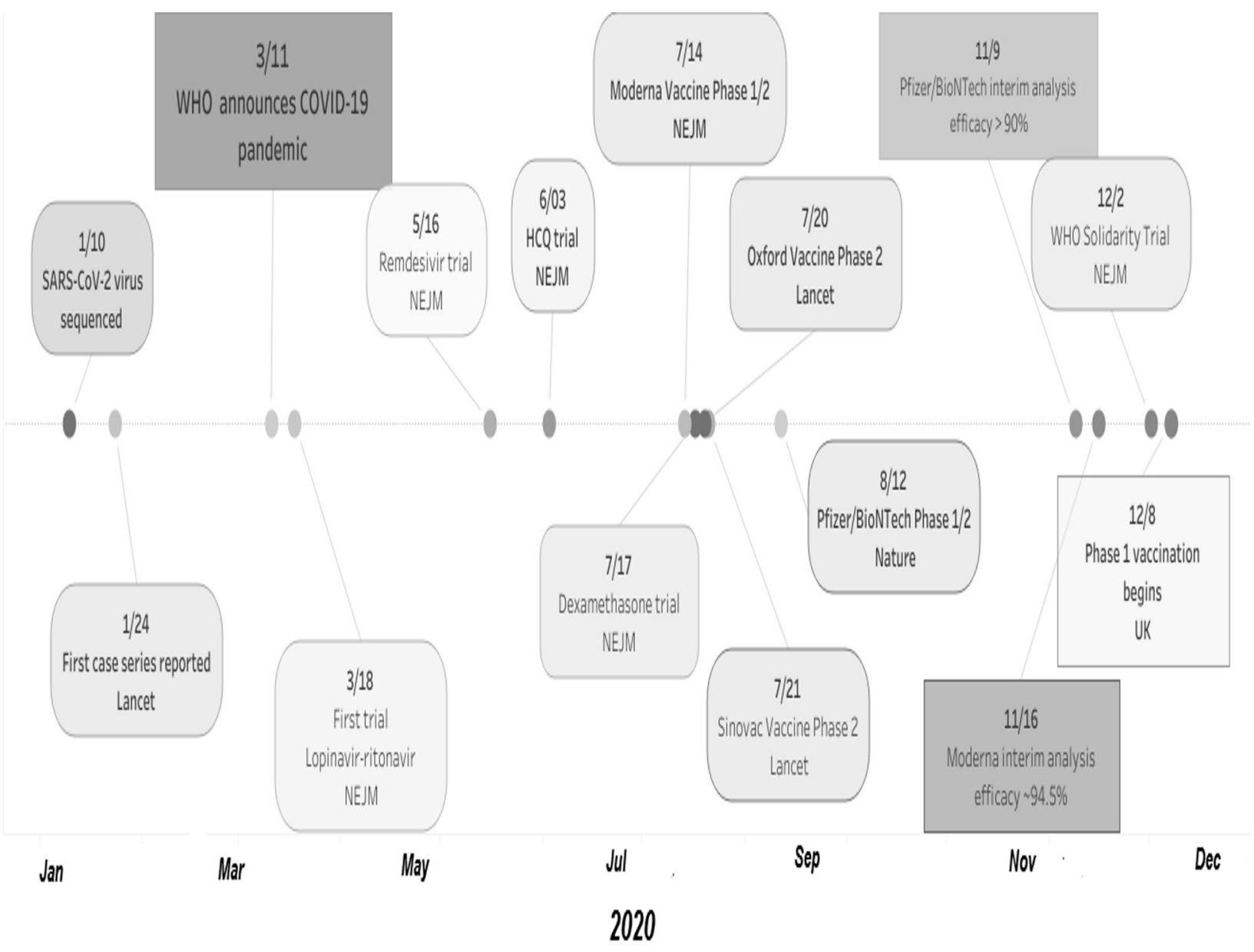

Figure 6. Timeline of the milestone events of the COVID-19 pandemic and related scientific production.

Regarding the countries with the greatest COVID-19 scientific output, the scenario is comparable to that of the overall global scientific production. Among the 11 countries with the greatest share of the global scientific production in 2019, 9 are also among those with the largest production on COVID-19. Only Japan and Russia were not included in the two rankings, being replaced by Spain and Brazil. Interestingly, three countries that were heavily hit by COVID-19, i.e., the US, Italy, and England, have shown the capacity to increase their scientific production, with a relevant increment in the share of scientific output. Together, these three countries account for about $25 \%$ of the global scientific production and have contributed about 50\% of the scientific output on COVID-19. This impressive increment might reflect the presence of cutting-edge research institutes and universities in these countries, which allowed a rapid response to this unparalleled crisis. For instance, among the 20 most productive institutions, $60 \%$ are from these countries ( 6 from the US, 5 from England, and one from Italy). China also had three institutions among the 20 most productive research institutes. We believe that this fast pace and huge amount of scientific production simultaneously involving many countries and institutions somewhat reflects the state of collaboration and healthy competition in the current world scientific output. Moreover, these leader countries have the concentration 
of scientific skill, technical knowledge and productive capacity that has allowed them to engage in an immediate response to an acute public health emergency. Unfortunately, the information regarding multicenter studies was not readily available in the WoS database. However, we found about 90,000 registries of countries for these 60,803 articles. Thus, we may infer that about one third of these studies are collaborative efforts involving the participation of research institutions from two or more countries. Interestingly, Fry et al. (2020) evaluated the trends in international collaboration during the first months of the COVID-19 pandemic and demonstrated that the event shifted the geographic loci of coronavirus research, as well as the structure of scientific teams, narrowing team membership and favoring consolidated structures.

This huge amount of scientific output is scattered through about 6,133 journals including a vast array of disciplines from basic science to the clinical front line. The first report from Chinese physicians in the front line was published online in Lancet on January, 24 (Huang et al. 2020). The authors described a cohort of 41 patients who were identified as having laboratory-confirmed 2019-nCoV infection. This report was followed by several papers that described the clinical and epidemiological features of patients in China (Guan et al. 2020). On February 3, Zhou et al. (2020) reported the identification, characterization, and full-length genome of a new coronavirus (2019-nCoV) obtained from five patients at an early stage of the outbreak. Subsequently, as expected, the most prestigious journals took the leadership in the process. Among 6,133 journals, 12 (0.2\%) have already published more than 250 articles. Interestingly, 6 of these journals are among those with the highest impact factor in Medicine or Multidisciplinary Sciences: NEJM (IF 2019, 76),
Lancet (60), JAMA (45), Nature (42), Science (41), and BMJ (30). An aspect of particular concern was raised regarding the impact of this fast increment in the volume of scientific production on journal standards. A number of manuscripts have been submitted to journals within such a short time that some leading journals have changed their process of evaluation. For example, Bauchner et al. (2020) reported that from January 1 to June 1, 2020, more than 11,000 manuscripts were submitted to JAMA, compared to approximately 4,000 manuscripts submitted during the same period in 2019 . Consequently, in the midst of the pandemic, the process of manuscript evaluation has been modified by many journals. For instance, in JAMA, for manuscripts that were judged as essentially descriptive, review has primarily been internal, by JAMA editors. External peer review has been conducted only for research manuscripts whose results were likely to "influence clinical practice or public health policy" (Bauchner et al. 2020). Since the pandemic began, an atypical volume of manuscripts has overwhelmed other prestigious journals. The Lancet is receiving three times the usual number of papers and the NEJM has fielded as many as 200 submissions in a day, according to their editors. In the context of a rapid increase in cases, hospitalizations, and deaths from COVID-19, clinicians, patients, policymakers, and the public at large are understandably eager for results of studies of prognosis, diagnosis, and treatment (Saitz \& Schwitzer 2020). Although rapid publication of clinically relevant information during a pandemic is obviously pivotal, publishing results that are not valid can do much harm. In this regard, for instance, two of the most prestigious clinical journals (NEJM and Lancet) were victims of a fraud with an immense repercussion in the press and social media (Ledford \& Van Noorden 2020, Servick \& Enserink 2020). The same research 
team published the papers about controversial aspects of COVID-19 treatment (Mehra et al. 2020a, b). Both papers were rapidly retracted, but in a polarized political atmosphere this fact ultimately contributed to undermining the public trust in science.

Regarding the subjects of the papers, our search has shown that the timeline follows the flow of the classic description of a new disease. At the outset, there was a predominance of papers with the description of the clinical characteristics and epidemiological data derived from the first cases series in China (Chen et al. 2020, Lu et al. 2020b). Soon after, from the epidemiological perspective, articles emerged reporting predictive models of the spread of the disease and stressing the risk of the worldwide collapse of the health systems (Flaxman et al. 2020, Dehning et al. 2020). On the clinical front, many of the elusive pathophysiological mechanisms involved have been investigated and the groups at risk for severe disease were identified (Williamson et al. 2020). Concomitantly, studies of the molecular aspects of the virus and its mechanisms of transmission have also emerged (Moghadas et al. 2020). The biology of SARS-CoV-2 has been intensively scrutinized, and its pivotal proteins have been described (Cyranoski 2020). In addition, the fundamental aspects of the human immune response to the virus have been progressively elucidated (Gussow et al. 2020, Barnes et al. 2020, Yang et al. 2020). With the disease spreading across Europe and North America, papers describing large case series from these regions came out, adding some new insights on risk factors and patient management (Cummings et al. 2020, Grasselli et al. 2020).

Brazil consolidated its place as a highquality scientific producer during the COVID-19 pandemic, being one of the 12 countries accounting for $95 \%$ of the world scientific output in 2020. For instance, genome sequencing and analysis of SARS-CoV-2 occurred only 48 hours after the first confirmed COVID-19 case in Brazil (Jesus et al. 2020). Affiliation ranking showed the overwhelming predominance of federal institutions, pointing to the undeniable role of public funding to national research and development. Indeed, the three most important funding agents - CNPq, CAPES and FAPESP are public institutions strictly, persevering on scientific development despite the continuous scrapping of higher education in the country (Oliveira et al. 2020). The importance of Brazilian federal institutions and public funding is highlighted by the seventeen ongoing vaccine development research, all taking place or being associated with federal institutions, according to the Ministry of Health. Because of chronic underfunding, vaccine-developing programs experience important limitations and delays, with poor literature being published on vaccine and clinical trials in 2020 even though Brazil stands out internationally for its vaccine production and vaccination program. In addition to the underfunding of scientific research, pandemic management by the federal government put Brazilian Unified Health System to collapse several times. Endorsement of drug relocations without scientific evidence, contempt for social distance measures and a general disregard for the seriousness of the pandemic by the federal government got Brazil on the worse scenario in 2021, breaking daily records on death numbers and becoming an international threat on variant development (Palmeira et al. 2020). That is why the most cited Brazilian article in 2020 is so representative, as it deals with the fair allocation of scarce medical resources.

It is undeniable that several of these studies have already made fundamental contributions to our understanding of the many aspects of this novel highly contagious virus and of 
the virulent disease it causes, i.e., COVID-19. Moreover, based on the aforementioned epidemiological studies, the adoption of public health measures labeled nonpharmaceutical interventions (NPIs) may have spared many lives by preventing the collapse of health systems worldwide. For instance, based on data from 149 countries, Islam et al. (2020) reported that the incidence of COVID-19 decreased by an average of $13 \%$ in association with physical distancing interventions. Nevertheless, with the disease leaving in its wake millions of infected patients, thousands of deaths, and an economic toll in the trillions of dollars to date, an effective treatment and vaccine are urgently needed (Heaton 2020). In this regard, on March 18th, 2020, the Director-General of the WHO announced the launch of a multinational Phase III-IV clinical trial called SOLIDARITY to facilitate a rapid worldwide comparison of unproven treatments. Unfortunately, the SOLIDARITY trial revealed that remdesivir, hydroxychloroquine, lopinavir, and interferon regimens had little or no effect on hospitalized patients with Covid-19 (Consortium WHOST 2021). In the United Kingdom, investigators designed the RECOVERY trial involving hospitalized patients with COVID-19 in order to assess the efficacy of different treatments using a single endpoint, i.e., mortality within 28 days after randomization (Normand 2020). In addition, several other ongoing trials are investigating efficient treatment for the disease and its complications (Fauci et al. 2020). Using the terms COVID-19, SARS-CoV-2, 2019-nCov, and 2019 novel coronavirus in the ClinicalTrials.gov database, we identified 1,829 studies registered as clinical trials aiming to evaluate several drugs against COVID-19. Nevertheless, Pundi et al. (2020) reviewed these studies registered in ClinicalTrials.gov and demonstrated that, among the RCTs, only $29 \%$ were placebo-controlled, blinded studies and had the potential to result in a high level of evidence. In our analysis, we found only about $25 \%$ papers with the terms "vaccine" and "clinical trials" in the title. The first trial was published online on March 18 and evaluated the combination of two drugs (lopinavir-ritonavir) in hospitalized adult patients with severe COVID-19 in China (Cao et al. 2020). Of note, only one of these trials has reported so far a drug with clinical benefits against COVID-19 (Group et al. 2021). In addition, research centers across the globe are racing to develop a SARS-CoV-2 vaccine based on many strategic approaches such as the entire virus, a recombinant protein subunit, and an mRNA vaccine (Shin et al. 2020). After July 2020, the first reports of phase $1 / 2$ RCT of candidate vaccines were published showing promising results concerning safety and immunogenicity (Folegatti et al. 2020, Jackson et al. 2020, Zhu et al. 2020, Sahin et al. 2020). Remarkably, in December 2020, the reports of phase 3 RCT of two vaccines with a combined number of 67,000 participants were released (Polack et al. 2020, Voysey et al. 2020).

In conclusion, the response of the scientific endeavor to this global acute public health emergency has been impressively fast and robust. Many collaborative coordinated efforts have contributed to a reliable answer to this unprecedented challenge in modern times. This has been a truly collective effort by researchers all around the world, as a global community, struggling to bring knowledge to the front lines. In the context of scientific publishing, a welcome initiative at the onset of the COVID-19 crisis was the decision by the most prestigious publishers and journals to provide open access to the entire material concerning COVID-19 to the scientific community. The scientific and social impact of this decision need to be evaluated in further studies, but we may already infer that this large 
available material has contributed to enhance research around the world.

We are living through an unprecedented biopsychosocial crisis. COVID-19 continues to spread throughout the world, resulting in major disruptions of business, education and transportation, and permeating virtually every aspect of daily life (Fontanarosa \& Bauchner 2020). Millions of people have been affected by COVID-19, hundreds of thousands have experienced critical illness, and tens of thousands have died. Physicians, health care professionals, and health care systems around the world have been challenged like never before in recent times. As we approach the end of 2020, it is time to consider a balance of the achievements of science during this extraordinary year. The emblematic pace of events, from the first case series in China described on January 24 to the report of an impressively effective vaccine on December, 10, is a testament to the work of so many dedicated scientists and health care workers. This is perhaps an opportunity for the governments and general population to definitively understand the importance of science in their daily lives. We believe that the overview provided by the analysis of the first months of scientific response to the pandemic may contribute to further studies aiming to evaluate the impact and changes in the scientific endeavor for the next years in light of the forthcoming new world framework.

\section{Acknowledgments}

This study was partially supported by Conselho Nacional de Desenvolvimento Científico e Tecnológico (CNPq), grant 430246/2018-8, and Fundação de Amparo à Pesquisa do Estado de Minas Gerais (FAPEMIG), grant PPM-00435-18. The funding organizations had no role in the design and conduct of the study; collection, management, analysis, and interpretation of the data; and preparation, review, or approval of the manuscript. The authors declare that they have no competing interests.

\section{REFERENCES}

BARNES CO ET AL. 2020. Structures of Human Antibodies Bound to SARS-CoV-2 Spike Reveal Common Epitopes and Recurrent Features of Antibodies. Cell 182(4): 828-842.

BAUCHNER H, FONTANAROSA PB \& GOLUB RM. 2020. Editorial Evaluation and Peer Review During a Pandemic: How Journals Maintain Standards. JAMA 324(5): 453-454.

CAO B ET AL. 2020. A Trial of Lopinavir-Ritonavir in Adults Hospitalized with Severe Covid-19. N Engl J Med 382(19): 1787-1799.

CHEN N ET AL. 2020. Epidemiological and clinical characteristics of 99 cases of 2019 novel coronavirus pneumonia in Wuhan, China: a descriptive study. Lancet 395(10223): 507-513.

CONSORTIUM WHOST ET AL. 2021. Repurposed Antiviral Drugs for Covid-19 - Interim WHO Solidarity Trial Results. N Engl J Med 384(6): 497-511.

CORONAVIRIDAE STUDY GROUP OF THE INTERNATIONAL COMMITTEE ON TAXONOMY OF VIRUSES. 2020. The species Severe acute respiratory syndrome-related coronavirus: classifying 2019-nCoV and naming it SARS-CoV-2. Nat Microbiol 5(4): 536-544.

CUMMINGS MJ ET AL. 2020. Epidemiology, clinical course, and outcomes of critically ill adults with COVID-19 in New York City: a prospective cohort study. Lancet 395(10239): 1763-1770.

CYRANOSKI D. 2020. Profile of a killer: the complex biology powering the coronavirus pandemic. Editorial Material. Nature 581(7806): 22-26.

DEHNING J, ZIERENBERG J, SPITZNER FP, WIBRAL M, PINHEIRO NETO J, WILCZEK M \& PRIESEMANN V. 2020. Inferring change points in the spread of COVID-19 reveals the effectiveness of interventions. Science 369 (6500): eabb9789.

FAUCI AS, LANE HC \& REDFIELD RR. 2020. Covid-19-Navigating the Uncharted. Editorial Material. N Engl J Med 382(13): 1268-1269.

FLAXMAN S ET AL. 2020. Estimating the effects of nonpharmaceutical interventions on COVID-19 in Europe. Nature 584(7820): 257-261.

FOLEGATTI PM ET AL. 2020. Safety and immunogenicity of the ChAdOx1 nCoV-19 vaccine against SARS-CoV-2: a preliminary report of a phase $1 / 2$, single-blind, randomised controlled trial. Lancet 396(10249): 467-478.

FONTANAROSA PB \& BAUCHNER H. 2020. COVID-19-Looking Beyond Tomorrow for Health Care and Society. Editorial Material. JAMA 323 (19): 1907-1908.

FRY CV, CAI X, ZHANG Y \& WAGNER CS. 2020. Consolidation in a crisis: Patterns of international collaboration in early COVID-19 research. PLoS One 15(7): e0236307. GRASSELLI 
G ET AL. 2020. Baseline Characteristics and Outcomes of 1591 Patients Infected With SARS-CoV-2 Admitted to ICUS of the Lombardy Region, Italy. JAMA 323(16): 1574-1581.

GROUP RC ET AL. 2021. Dexamethasone in Hospitalized Patients with Covid-19 - Preliminary Report. N Engl J Med 384(8): 693-704.

GUAN W ET AL. 2020. Clinical Characteristics of Coronavirus Disease 2019 in China. N Engl J Med 382(18): 1708-1720.

GUSSOW AB, AUSLANDER N, FAURE G, WOLF YI, ZHANG F \& KOONIN EV. 2020. Genomic determinants of pathogenicity in SARS-CoV-2 and other human coronaviruses. Proc Natl Acad Sci USA 117(26): 15193-15199.

HEATON PM. 2020. The Covid-19 Vaccine-Development Multiverse. N Engl J Med 383(20): 1986-1988.

HUANG C ET AL. 2020. Clinical features of patients infected with 2019 novel coronavirus in Wuhan, China. Lancet 395(10223): 497-506.

ISLAM N, SHARP SJ, CHOWELL G, SHABNAM G, KAWACHI I, LACEY B, MASSARO JM, D'AGOSTINO SR RB \& WHITE M. 2020. Physical distancing interventions and incidence of coronavirus disease 2019: natural experiment in 149 countries. BMJ 370: $\mathrm{m} 2743$.

JACKSON LA ET AL. 2020. An mRNA Vaccine against SARSCoV-2 - Preliminary Report. N Engl J Med 383(20): 1920-1931.

JESUS JG ET AL. 2020. Importation and early local transmission of COVID-19 in Brazil. Rev Inst Med Trop S Paulo 62: e30.

LEDFORD H \& VAN NOORDEN R. 2020. High-profile coronavirus retractions raise concerns about data oversight. Nature 582(7811): 160

LU H, STRATTON CW \& TANG YW. 2020a. Outbreak of pneumonia of unknown etiology in Wuhan, China: The mystery and the miracle. J Med Virol 92(4): 401-402.

LU R ET AL. 2020b. Genomic characterisation and epidemiology of 2019 novel coronavirus: implications for virus origins and receptor binding. Lancet 395(10224): 565-574.

MEHRA MR, DESAI SS, KUY S, HENRY TD \& PATEL AN. 2020a. Retraction: Cardiovascular Disease, Drug Therapy, and Mortality in Covid-19. N Engl J Med 382(26): 2582.

MEHRA MR, DESAI SS, RUSCHITZKA F \& PATEL AN. 2020b. RETRACTED: Hydroxychloroquine or chloroquine with or without a macrolide for treatment of COVID-19: a multinational registry analysis. Lancet: doi 10.1016/ S0140-6736(20)31180-6.

MOGHADAS SM, FITZPATRICK MC, SAH P, PANDEY A, SHOUKAT A, SINGER BH \& GALVANI AP. 2020. The implications of silent transmission for the control of COVID-19 outbreaks. Proc Natl Acad Sci USA 117(30): 17513-17515.
NORMAND ST. 2021. The RECOVERY Platform. N Engl J Med 384(8): 757-758.

OLIVEIRA EA, JUNIOR HM, SIMÕES E SILVA AC, MARTELLI DRB \& OLIVEIRA MCL. 2020. Science funding crisis in Brazil and COVID-19: deleterious impact on scientific output. An Acad Bras Cienc 92: e20200700. https://doi. org/10.1590/0001-3765202020200700.

PALMEIRA VA, COSTA LB, PEREZ LG, RIBEIRO VT, LANZA K \& SIMÕES E SILVA AC. 2020. Do we have enough evidence to use chloroquine/hydroxychloroquine as a public health panacea for COVID-19? Clinics (Sao Paulo) 75: e1928.

POLACK FP ET AL. 2020. Safety and Efficacy of the BNT162b2 mRNA Covid-19 Vaccine. N Engl J Med 383(27): 2603-2615.

PUNDI K, PERINO AC, HARRINGTON RA, KRUMHOLZ HM \& TURAKHIA MP. 2020. Characteristics and Strength of Evidence of COVID-19 Studies Registered on ClinicalTrials. gov. JAMA Intern Med 180(10): 1398-1400.

SAHIN U ET AL. 2020. COVID-19 vaccine BNT162b1 elicits human antibody and TH1 T cell responses. Nature 586 (7830): 594-599.

SAITZ R \& SCHWITZER G. 2020. Communicating Science in the Time of a Pandemic. JAMA 324(5): 443-444.

SERVICK K \& ENSERINK M. 2020. A mysterious company's coronavirus papers in top medical journals may be unraveling. Science: doi:10.1126/science.abd1337.

SHIN MD ET AL. 2020. COVID-19 vaccine development and a potential nanomaterial path forward. Nat Nanotechnol 15: 646-655.

VOYSEY M ET AL. 2020. Safety and efficacy of the ChAdOx1 nCoV-19 vaccine (AZD1222) against SARS-CoV-2: an interim analysis of four randomised controlled trials in Brazil, South Africa, and the UK. Lancet 397(10269): 99-111.

WILLIAMSON EJ ET AL. 2020. Factors associated with COVID-19 death in 17 million patients using OpenSAFELY. Nature 584: 430-436.

WHO. 2020. Coronavirus disease 2019 (COVID-19): situation report - 51. World Health Organization.

YANG L, LIU S, LIU J, ZHANG Z, WAN X, HUANG B, CHEN Y \& ZHANG Y. 2020. COVID-19: immunopathogenesis and Immunotherapeutics. Signal Transduct Target Ther 5(1): 128.

ZHOU P ET AL. 2020. A pneumonia outbreak associated with a new coronavirus of probable bat origin. Nature 579 (7798): 270-273.

ZHU FC ET AL. 2020. Immunogenicity and safety of a recombinant adenovirus type-5-vectored COVID-19 vaccine in healthy adults aged 18 years or older: a randomised, double-blind, placebo-controlled, phase 2 trial. Lancet 396(10249): 479-488. 


\section{How to cite}

OLIVEIRA EA, OLIVEIRA MCL, MARTELLI DB, COLOSIMO EA, SILVA LR, LANZA K, MARTELLI-JÚNIOR H \& SILVA ACS. 2021. COVID-19 pandemic and the answer of science: a year in review. An Acad Bras Cienc 93: e20210543. DOI 10.1590/0001-3765202120210543.

Manuscript received on April 19, 2021;

accepted for publication on July 5, 2021

\section{EDUARDO A. OLIVEIRA ${ }^{1}$}

https://orcid.org/0000-0002-5642-7164

\section{MARIA CHRISTINA L. OLIVEIRA ${ }^{1}$}

https://orcid.org/0000-0002-2511-6769

\section{DANIELLA B. MARTELLI ${ }^{2}$}

https://orcid.org/0000-0002-3979-7497

\section{ENRICO ANTÔNIO COLOSIMO 3}

https://orcid.org/0000-0001-8705-4674

\section{LUDMILA R. SILVA 4}

https://orcid.org/0000-0002-2097-3809

\section{KATHARINA LANZA}

https://orcid.org/0000-0001-7488-6906

\section{HERCÍLIO MARTELLI-JÚNIOR ${ }^{2}$}

https://orcid.org/0000-0001-9691-2802

\section{ANA CRISTINA SIMÕES E SILVA ${ }^{1}$}

https://orcid.org/0000-0001-9222-3882

${ }^{1}$ Federal University of Minas Gerais (UFMG), Interdisciplinary Laboratory of Medical Investigation, Faculty of Medicine, Alfredo Balena, 190, 30130100 Belo Horizonte, Minas Gerais, Brazil ${ }^{2}$ State University of Montes Claros (Unimontes), Health Science/Primary Care Postgraduate Program, Prof. Rui Braga, s/n, 39401-089 Montes Claros, MG, Brazil

${ }^{3}$ Federal University of Minas Gerais, Department of Statistics, Pres. Antônio Carlos 6627, 31270-901 Belo Horizonte, MG, Brazil ${ }^{4}$ Federal University of Minas Gerais, Health Science/ Postgraduate Program in Nursing. School of Nursing, Alfredo Balena 190, 30130-100 Belo Horizonte, MG, Brazil
Correspondence to: Ana Cristina Simões e Silva

E-mail: acssilva@hotmail.com

\section{Author contributions}

Conceptualization: EAO, MCLO; Methodology: EAO, MCLO, EAC,ACSS Investigation: EAO, MCLO, ACSS, DRM, HMJ, LRS; Formal analysis: EAO, MCLO, ACSS, DRM, HMJ, LRS, EAC, KL; Writing original draft preparation: EAO, HMJ; Writing - review and editing: EAO, MCLO, ACSS, HMJ, KL; Data Curation: EAO, MCLO, Supervision: EAO and ACSS. Each author contributed important intellectual content during manuscript drafting or revision and accepts accountability for the overall work by ensuring that questions pertaining to the accuracy or integrity of any portion of the work are appropriately investigated and resolved. EAO takes responsibility regarding the fact that this study has been reported honestly, accurately, and transparently.

\section{(cc) BY}

